\title{
Perihilar Bile Duct Cancer pT2b TNM
} Finding v7

National Cancer Institute

\section{Source}

National Cancer Institute. Perihilar Bile Duct Cancer pT2b TNM Finding V7. NCI

Thesaurus. Code C90229.

Perihilar bile duct cancer with tumor invading adjacent hepatic parenchyma. (from AJCC 7th Ed.) 